\title{
HIGH STRENGTH GEOPOLYMERS PRODUCED FROM COAL COMBUSTION FLY ASH
}

\author{
H.W. NUGTEREN ${ }^{1, *}$ \\ V.C.L. BUTSELAAR-ORTHLIEB ${ }^{2}$ \\ M. IZQUIERDO 3
}

\author{
${ }^{1}$ Section Product and Process Engineering, \\ Department of Chemical Engineering, \\ Delft University of Technology \\ Julianalaan 136, 2628 BL Delft, The Netherlands \\ ${ }^{2}$ Section NanoStructured Materials, \\ Department of Chemical Engineering, \\ Delft University of Technology \\ Julianalaan 136, 2628 BL Delft, The Netherlands \\ ${ }^{3}$ Institute of Earth Sciences "Jaume Almera" - CSIC \\ Lluis Solé Sabaris s/n 08028 Barcelona, Spain
}

Received: 29/07/08

Accepted: $11 / 11 / 08$ *to whom all correspondence should be addressed: e-mail: : $\underline{\text { h.w.nugteren@tudelft.nl }}$

\begin{abstract}
High strength geopolymers were produced from coal combustion fly ashes. These matrices reached compressive strength values over $100 \mathrm{MPa}$, much stronger and denser than obtained by using Portland Cement binders. Size fractions were obtained by size separation techniques and the relationship between strength and particle size was investigated. The differences in compressive strength measured in the geopolymers made from fine fractions, the original fly ash and a coarse fraction of the same ash, were not significantly higher than the variation found for a reference geopolymer material. Therefore, a direct size-strength relationship could not be proven. Moreover, the chemistry and the $\mathrm{pH}$ of the fractions also varied, and this might as well has played a role in the strength development.
\end{abstract}

KEYWORDS: fly ash, geopolymer, compressive strength, workability, particle size.

\section{INTRODUCTION}

Geopolymers are inorganic polymeric materials with a chemical composition similar to zeolites but possessing an amorphous structure. Geopolymers may be seen as man-made rocks. They can be produced by reacting solid aluminosilicates with a highly concentrated aqueous alkali hydroxide or silicate solution. The chemistry and terminology of inorganic polymers was first discussed in detail by Davidovits (1999). Since the first mention of the term 'geopolymer' by Davidovits (1991), extensive research in this field has been carried out, also by authors using different wordings for the same kind of materials. 'Low-temperature aluminosilicate glass' (Rahier et al., 1996), 'alkali-activated cement' (Palomo and López dela Fuente, 2003), 'alkali-bonded ceramic' (Mallicoat et al., 2005), 'inorganic polymer concrete' (Sofi et al., 2007), and 'hydroceramic' (Bao et al., 2005) are some of the frequently occurring designations.

Geopolymers form three-dimensional disordered frameworks of the tecto-aluminosilicate type with the general empirical formula $\mathrm{M}_{\mathrm{n}}\left[-\left(\mathrm{SiO}_{2}\right)_{\mathrm{z}}-\mathrm{AlO}_{2}\right]_{\mathrm{n}} \cdot \mathrm{wH}_{2} \mathrm{O}$, in which $\mathrm{n}$ is the degree of polycondensation, and $\mathrm{M}$ is predominantly a monovalent cation $\left(\mathrm{K}^{+}, \mathrm{Na}^{+}\right)$, although $\mathrm{Ca}^{2+}$ may replace two monovalent cations in the structure (Davidovits, 1999). In the same paper, Davidovits states that although the $\mathrm{SiO}_{2} / \mathrm{Al}_{2} \mathrm{O}_{3}$ ratio $\mathrm{z}$ is 1,2 or 3 for the poly(sialate)-, poly(sialate-siloxo)- and poly(sialate-disiloxo)-chains, $z$ can also be larger than 3 (up to 32 ), which can be explained by cross linking of polysilicate chains, sheets or networks with a sialate link (-Si-O-Al-O-). 
Usually, geopolymers are synthesised at relatively low temperatures from meta-kaolinite. The smaller the particle size of the starting material the higher the reactivity and the geopolymerisation rate will be. Duxson et al.(2007) gave an overview of geopolymer technology. Further information is available in the first book on geopolymers (Davidovits, 2008).

The Si/Al ratio, the predominant amorphous structure, and the fine particle size of fly ashes, are appropriate for the synthesis of geopolymers with a Si/Al ratio of 1 or 2. Successful attempts of using fly ash for the synthesis of geopolymers were reported at the international conferences on geopolymers (Davidovits et al., 1999; Lukey, 2002; Davidovits, 2005). An overview of geopolymer chemistry, synthesis and applications was presented at the WOCA conferences by Nugteren et al. $(2005 ; 2007)$.

The present work is carried out in the framework of a project (GEOASH), sponsored by the European Coal and Steel Community. The GEOASH project aims to produce new geopolymeric matrices, stronger and denser than obtained by using Portland Cement binders, that can be used for the long term stabilization of inorganic toxic waste. The particular work presented in this paper deals with a study investigating the benefit that might be taken from the presence of the smallest particles of fly ash. For this reason fine fractions were separated from fly ash by wind sifting. The impact of particle size on strength was studied by preparing geopolymer samples of different fractions from a few selected fly ashes. Another new feature was the curing to take place at ambient temperatures.

\section{MATERIALS AND METHODS}

From a selection of 17 European coal (co-)combustion ashes, an alkaline fly ash from a major Dutch power station was selected and used for this study. The fly ash was produced from the combustion of a coal blend with $14 \%$ co-combustion of biomass (11\% wood and $3 \%$ palm pits). The chemical analysis of the fly ash, together with the analysis of the blast furnace slag that was used for the geopolymerisation experiments, are given in Table 1.

Table 1. Chemical composition of fly ash and slag

\begin{tabular}{lll}
\hline & Fly ash TUD-1 & Slag \\
\hline $\mathrm{SiO}_{2}$ & 48.94 & 37.17 \\
$\mathrm{Al}_{2} \mathrm{O}_{3}$ & 27.76 & 11.83 \\
$\mathrm{TiO}_{2}$ & 2.44 & 0.58 \\
$\mathrm{Fe}_{2} \mathrm{O}_{3}$ & 7.90 & 0.34 \\
$\mathrm{MnO}$ & 0.04 & \\
$\mathrm{CaO}$ & 6.03 & 42.04 \\
$\mathrm{MgO}$ & 1.77 & 7.48 \\
$\mathrm{~K}_{2} \mathrm{O}$ & 0.84 & \\
$\mathrm{Na} 2$ & 0.58 & 0.24 \\
$\mathrm{P}_{2} \mathrm{O}_{5}$ & 1.11 & \\
$\mathrm{LOI}$ & 2.39 & \\
\hline $\mathrm{SiO}_{2} / \mathrm{Al}_{2} \mathrm{O}_{3}$ & 1.76 & \\
\hline
\end{tabular}

A centrifugal zigzag classifier (100 MZR Alpine) was used to produce batches of fine fractions. By varying the sifter gear (the rotational speed of the disc) and the air flow, different cut points ( $d_{97}$ of the fine fraction) could be obtained. Four fine fractions were produced for different instrument settings from fly ash TUD1. Together with the original fly ash and the coarse residue after separating the fine fraction, six samples resulted to be used for the geopolymerisation trials. The overview of the size characteristics is given in Table 2. Figure 1 shows the size distributions of the six samples. All particle size measurements were performed with a Malvern Mastersizer instrument in ethanol using sonication until a stable response was obtained.

The yield, the amount produced from the feed (in wt\%), is inevitably decreasing when separating finer fractions. As can be seen from Table 2, for the finest fractions this can even 
be less than $10 \%$, since the original ash only contains small amounts of such fine particles. It was further calculated that in general from the fine particles present in the feed, between 20 and $70 \%$ were recovered in the separated fractions.

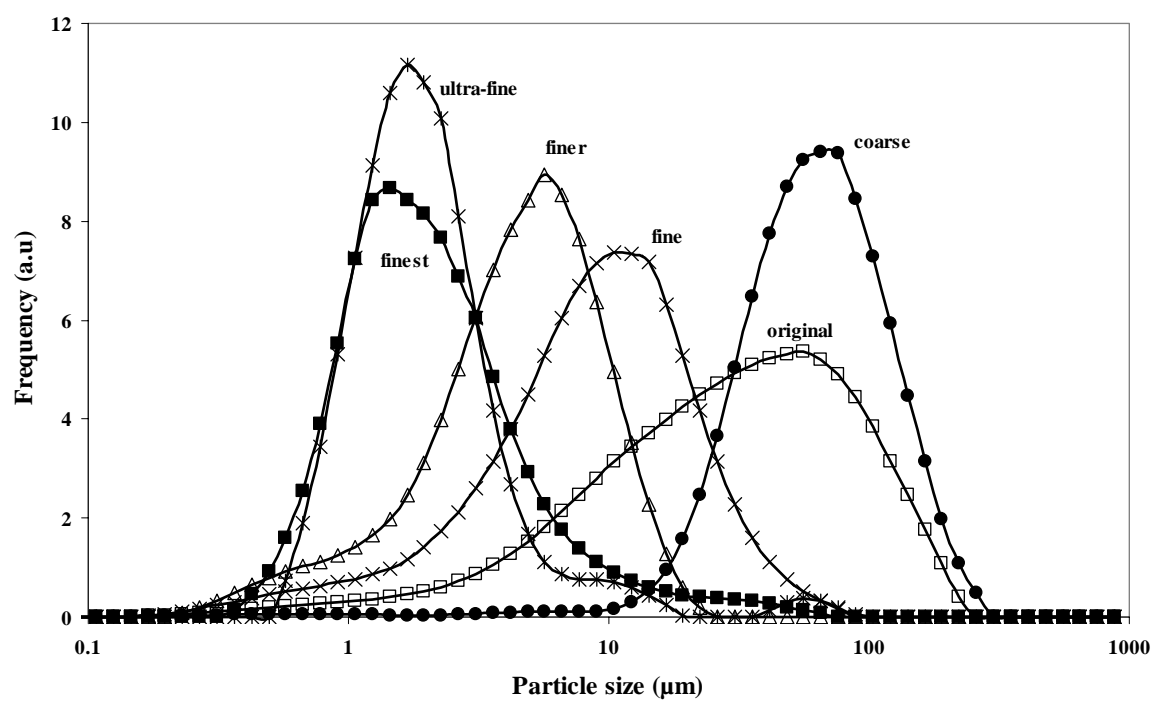

Figure 1. Size distributions of the samples produced from fly ash TUD1

Table 2. Size characterisation of the used fly ash and the samples thereof

\begin{tabular}{|c|c|c|c|c|c|}
\hline \multirow[t]{2}{*}{ Sample } & \multirow{2}{*}{$\begin{array}{l}\text { Yield } \\
\text { (\% of } \\
\text { feed) }\end{array}$} & \multicolumn{3}{|c|}{$\begin{array}{l}\text { Particle size } \\
\text { characteristics }\end{array}$} & \multirow{2}{*}{$\begin{array}{l}\text { Cut } \\
\text { Point } \\
d_{97}\end{array}$} \\
\hline & & $d_{10}$ & $d_{50}$ & $d_{90}$ & \\
\hline Coarse & & 23 & 55 & 115 & \\
\hline TUD-1 Original & & 3.4 & 24 & 86 & \\
\hline Fine & 41 & 1.9 & 9.3 & 25 & 36 \\
\hline Finer & 19 & 1.2 & 4.3 & 10 & 14 \\
\hline Finest & 6 & 0.9 & 2.2 & 4.6 & 6.5 \\
\hline Ultra-fine & 4 & 0.9 & 1.7 & 3.2 & 4.5 \\
\hline
\end{tabular}

Geopolymers were produced from mixes consisting of fly ash, blast furnace slag, potassium

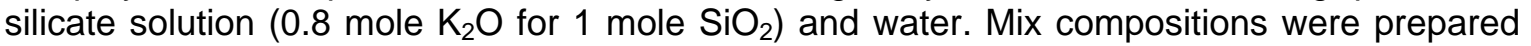
such that the pastes were just workable for the time required to mould 8 cylinders of $29 \mathrm{~mm}$ diameter to a height of about $25 \mathrm{~mm}$. This resulted in geopolymer rod samples of approximately $30 \mathrm{~g}$ each. The mix proportions K-silicate:Water:Slag (10:10:15 on a weight basis) were kept constant, whereas the fly ash content was varied and optimised to give the best results. The mix is hold thixotropic by performing mixing and pouring in the moulds, while keeping it on a shaker. The closed Teflon containers with the mixes were cured for 28 days at room temperature, before compression tests were performed.

Davya 30, a commercial metakaolinite-based geopolymer from Cordi-Géopolymère, was used as a reference material.

Compressive strength measurements were done on a Zwick Z100 tensiometer, stress controlled compression instrument (crosshead SN 149992), using testXpert software. The compression tests were performed in batches of 4 cylinders. The lowest result was discarded and the remaining three results averaged to obtain the value for the sample. The highest result was also retained and recorded in the graphs.

\section{RESULTS AND DISCUSSION}

The Davya geopolymer used as a reference is an easy to mix and to handle geopolymeric material. The ideal mix proportions are known and applied in the preparation of samples. Cylinders from this material can thus be made with a high degree of reproducibility and it is 
assumed that variations in compressive strength obtained are only due to natural variation in the material, the curing, and random errors in the compression tests. In a test varying the sample rod height between 17 and $31 \mathrm{~mm}$, it was found that the height of the samples did not have a significant influence on the compressive strength measured, as can be seen from Figure 2. The compressive strength of this geopolymer, measured after 3 weeks, had an average of $87 \mathrm{MPa}$ with a standard deviation of $7.4 \mathrm{MPa}$. In a further test, 10 samples were prepared with a rod height of $25 \mathrm{~mm}$. Those were measured after 28 days and gave an average strength of $101 \mathrm{MPa}$ with a standard deviation of $4.4 \mathrm{MPa}$. These tests gave an idea about the best possible accuracy and precision that can be obtained with the type of geopolymer samples made for this study.

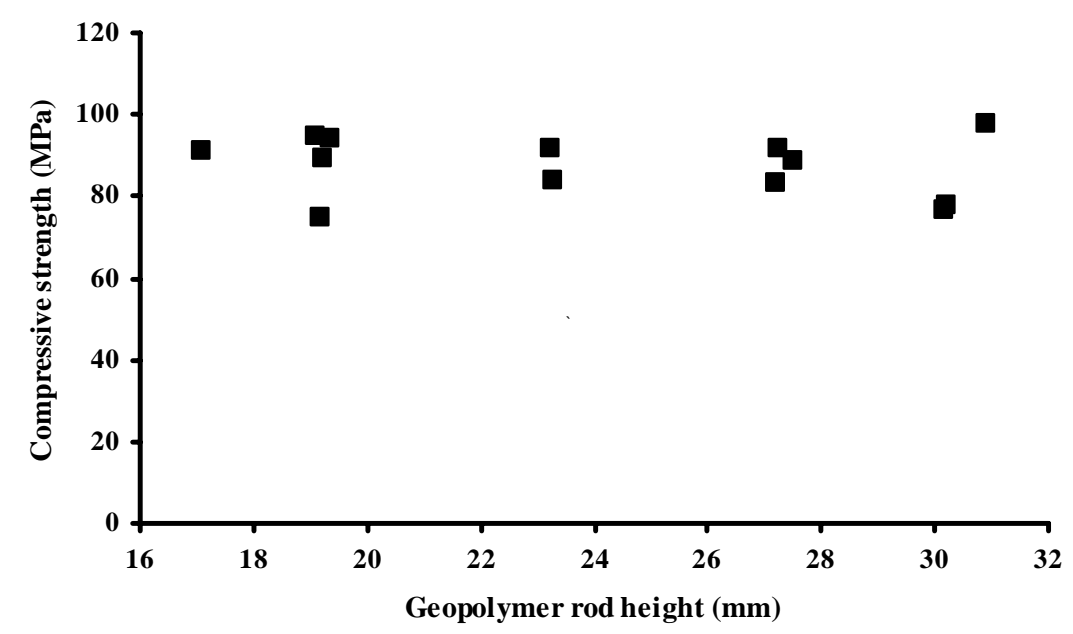

Figure 2. Compressive strength for Davya 30 geopolymer rods of $29 \mathrm{~mm}$ diameter for different sample heights

However, making geopolymers from fly ash is less straight forward than for the Davya material. The final compressive strength depends on the mix used, that is the amount of fly ash that is added to the fixed amount of slag, K-silicate solution and water. In practice, as much as possible fly ash was incorporated in the mix in order to obtain a stiff paste. By adding more and more fly ash, there seems to be a subtle turn-over point from where the mix changes from thixotropic to dry and inconsistent. This determines the upper limit of the operation window. The lower limit of the window is less well defined. By putting less fly ash in the mix, the paste becomes more fluid until it reaches a point that no good hardening can be expected. The workability is thus determined by the amount of ash added. Another difficulty is the limited working time, that is the time that is available from the mixing until hardening occurs to the point that the paste becomes unworkable. For most of the mixes this is in the order of 15 to 30 minutes.

As an example for the dependence of the compressive strength on the mix proportions, in Figure 3 the compressive strengths found for different mixes for the original sample are shown. As can be seen, the highest strength is found for the highest workable mix at 43 (Ksilicate:Water:Slag:Fly ash 10:10:15:43 on a weight basis). Further increase of the amount of fly ash makes the paste unworkable.

It was found that for the different fractions of the same fly ash TUD1, the operational windows were different and also the mix at which highest compressive strength was obtained was different. Therefore, in a number of preliminary tests, for each size fraction the optimum mix had to be determined. This could only be done approximately, because the extent of testing was limited due to the availability of samples for the finest fractions. This is another reason why the spreading of results is expected to be higher than for the Davya material. If mixing, pouring, curing or compressive strength measurements are carried out in an inappropriate manner or not under the optimal conditions, early failure will result and therefore low compressive strength values will be obtained. Therefore the maximum compressive strength 
values do have importance, as those are values that can under perfectly controlled conditions be reached.

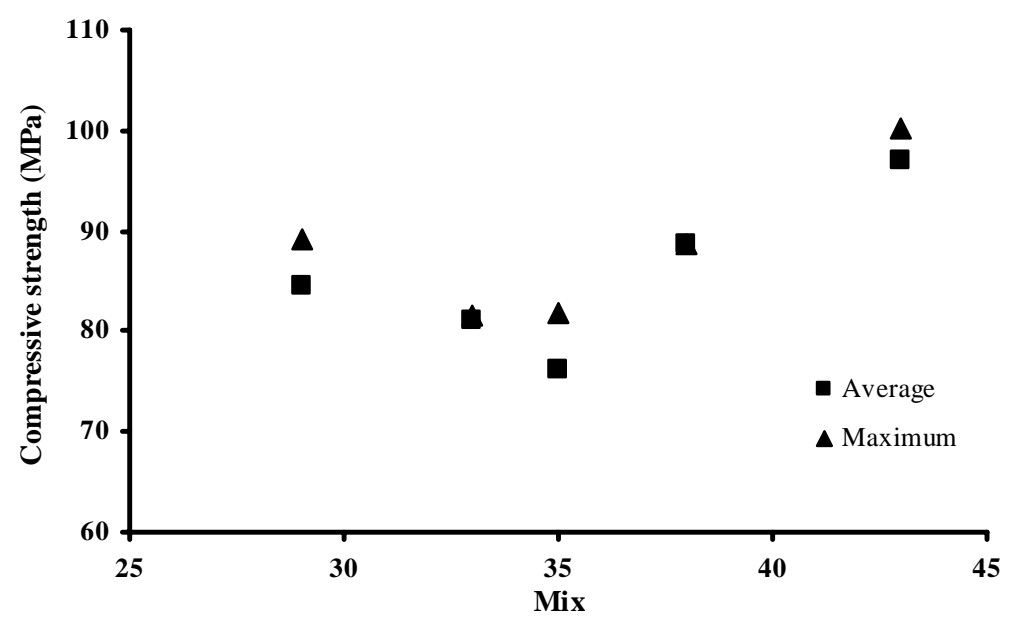

Figure 3. Compressive strength for different mix proportions (K-silicate:Water:Slag:Fly ash = 10:10:15:Mix on a weight basis)

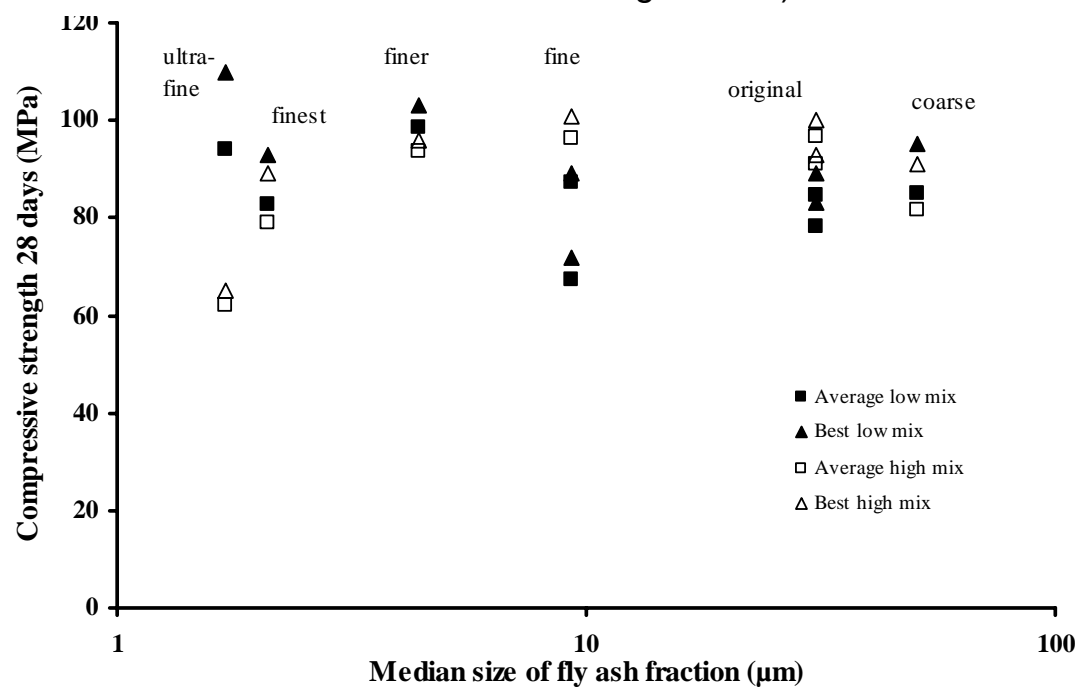

Figure 4. Compressive strength for geopolymers produced from different size fractions from fly ash TUD1. Open symbols represent the values for the maximum workable mix, whereas closed symbols are for lower mixes

Figure 4 shows the results of compressive strength obtained for the different size fractions of the fly ash TUD1. For each size fraction, the average compressive strength and the maximum value obtained were plotted for the highest workable mix and for a lower mix that gave a much more watery and easier workable paste. For the fine and the original samples results from duplicate tests were plotted as well. There is no clear trend of increasing compressive strength with decreasing particle size. Remarkable is that the 'coarse' fraction performs similar to the 'finest' fraction. Comparing this graph with Figure 2 for the reference geopolymer Davya 30, it becomes clear that a similar kind of spreading of the data occurs. Taking all data together, the average strength gives $85 \pm 11 \mathrm{MPa}$ and the maximum strength $91 \pm 11 \mathrm{MPa}$. The standard deviation is indeed a bit higher than for the Davya, as was expected from the more complex operation to make the geopolymers from the fly ash samples.

As discussed earlier (Nugteren et al., 2007), the pH of the size fractions decreases with the particle size. Generally, it is assumed that reactive phases available to dissolution are located on the surface of the ash particles. Because small particles have a higher surface to volume ratio than large particles, and therefore a higher specific surface area compared to large 
particles, it is expected that the fine fractions would have the higher $\mathrm{pH}$. So, the fact that fine fractions have a lower $\mathrm{pH}$ than the original sample seems counterintuitive. The main $\mathrm{pH}$ determining component in fly ash is free lime $(\mathrm{CaO})$. Bulk chemical and mineralogical analyses of the fractions show that the chemistry and mineralogy change with particle size as well. The free lime content increases with increasing particle size and this is also suggested by minor traces of lime in XRD patterns of the coarse fractions. Thus, the presence of relatively large $\mathrm{CaO}$ particles in the ash, is probably responsible for the observed $\mathrm{pH}$ differences. This phenomenon was also found in other ashes used in the project. Besides the $\mathrm{CaO}$ content also the $\mathrm{MgO}$ and $\mathrm{Fe}_{2} \mathrm{O}_{3}$ content increases with increasing particle size, whereas the $\mathrm{Na}_{2} \mathrm{O}, \mathrm{K}_{2} \mathrm{O}, \mathrm{P}_{2} \mathrm{O}_{5}$ and $\mathrm{SO}_{3}$ content markedly decreases. The $\mathrm{Al}_{2} \mathrm{O}_{3}$ content decreases slightly with particle size.

The $\mathrm{pH}$ and chemistry variations may influence the strength of the resulting geopolymers. If this influence was opposite to the effect of particle size, then particle size may still have its impact, although this can not be depicted from Figure 4.

A possible explanation for the lack of clear relation between strength and particle size may be that the conditions and mixing proportions do not allow full benefit of the available fly ash surface area. As can be seen from Figure 4, for the small size fractions the highest strengths are found when less fly ash is used in the mix (low mix). The fresh paste is easier to handle and there is more time for dissolution of the fly ash before the mix starts to set. For the coarse fractions, it appears that a maximum amount of fly ash in the mix (high mix) is favourable for getting high geopolymer strength. The solid:liquid ratio may be of influence on the amount of free lime dissolved during mixing. The dissolution of free lime is known to influence the geopolymeric reaction in a negative way. A high mix will probably limit the dissolution of free lime, predominantly present in the coarser size fractions, and therefore be in favour of high strength.

\section{CONCLUSIONS}

High strength geopolymeric matrices, up to compressive strength values of over $100 \mathrm{MPa}$, were produced from mixtures of coal fly ash, blast furnace slag, a potassium silicate solution and water, in which the fly ash is the majority component. The hypothesis that fine fractions of the same ash would produce stronger material could not be confirmed by the experiments carried out. Variation of compressive strength for prepared size fractions (median sizes varying from 1.7 to $55 \mu \mathrm{m}$ ) turned out to be comparable to the variation found for the reference geopolymer Davya 30 . Chemistry and $\mathrm{pH}$ are different for the different size fractions produced and could have had an impact on the performance as well. Furthermore, the mix proportions had to be adjusted for each fraction to give maximum strength, another factor that might have influenced the results.

\section{ACKNOWLEDGEMENT}

The work presented here concerning the GEOASH project was carried out with a financial grant from the Research Fund for Coal and Steel of the European Community. The GEOASH project is known under the contract number RFC-CR-04005.

\section{REFERENCES}

- Bao Y., Grutzeck M.W. and Jantzen C.M., (2005), Preparation and properties of Hydroceramic Waste Forms made with simulated Hanford low-activity waste. Journal of the American Ceramic Society, 88, 3287-3302.

- Davidovits J., (1991), Geopolymers: Inorganic polymeric new materials. Journal of Thermal Analysis, 37, 1633-1656.

- Davidovits J., (1999), Chemistry of geopolymeric systems, terminology, In: Proceedings Second International Conference, Géopolymère '99, Davidovits, J., Davidovits, R. and James, C. (Eds.), Institut Géopolymère, Saint-Quentin, France, 9-39.

- Davidovits J., Davidovits R. and James C., (Eds.), (1999), Proceedings Second International Conference, Geopolymère '99, Institut Géopolymère, Saint Quentin, France. 
- Davidovits J., (Ed.), (2005), Geopolymer, Green Chemistry and Sustainable Development Solutions; Proceedings of the World Congress Geopolymer 2005, Institut Géopolymère, Saint Quentin, France.

- Davidovits J., (2008), Geopolymer Chemistry and Applications. Institut Géopolymère, Saint-Quentin, France.

- Duxson P., Fernández-Jiménez A., Provis J.L., Lukey G.C., Palomo A. and van Deventer J.S.J., (2007), Geopolymer technology: the current state of the art. Journal of Materials Science, 42, 2917-2933.

- Lukey G.C., (Ed.), (2002), Proceedings of the International Conference Geopolymers 2002, University of Melbourne, Australia.

- Mallicoat S., Sarin P. and Kriven W.M., (2005), Novel, alkali-bonded, ceramic filtration membranes. Ceramic Engineering and Science Proceedings, 26, 37-41.

- Nugteren H.W., Davidovits J., Antenucci D., Fernandez-Pereira C. and Querol X., (2005), Geopolymerization of fly ash. In: World of Coal Ash Conference, Lexington, Kentucky, USA. (Paper \#147 on CD).

- Nugteren H.W., Barcena J.F., Butselaar-Orthlieb V.C.L. and Schouten L.A., (2007), Influence of Particle Size Distribution on the Compressive Strength of Geopolymers Produced from Coal (co-)Combustion Fly Ashes. In: World of Coal Ash Conference, Covington, Kentucky, USA. (Paper \#128 on CD).

- Palomo A. and López de la Fuente J.I., (2003), Alkali-activated cementitous materials: Alternative matrices for the immobilisation of hazardous wastes; Part I. Stabilisation of boron. Cement and Concrete Research, 33, 281-288.

- Rahier H., van Mele B., Biesemans M., Wastiels J. and Wu X., (1996), Low-temperature synthesized aluminosilicate glasses. Journal of Materials Science, 31, 71-85.

- Sofi M., van Deventer J.S.J., Mendis P.A. and Lukey G.C., (2007), Bond performance of reinforcing bars in inorganic polymer concrete (IPC). Journal of Materials Science, 42, 3107-3116. 